\title{
Research Paper \\ The efficacy of adler cognitive-social education on the interaction of mothers and adolescents with social anxiety disorder
}

Tahereh Najafi Fard ${ }^{\mathbf{1}}$, Hamid Alizadeh ${ }^{\mathbf{2}}$, Ahmad Borjali $\mathbf{3}^{\mathbf{3}}$ Mohammad Asgari
1. Ph.D Student of Psychology and Exceptional Children Education, Allameh Tabataba'i University, Tehran, Iran.
2. Professor, Department of Psychology and Exceptional Children Education, Allameh Tabataba'i University, Tehran, Iran.
3. Professor, Department of Psychology, Allameh Tabataba'i University, Tehran, Iran.
4. Associate Professor, Department of Assessment and Measurement, Allameh Tabataba'i University, Tehran, Iran.

Citation: Najafi Fard T, Alizadeh H, Borjali A, Asgari M. The efficacy of adler cognitive-social education on the interaction of mothers and adolescents with social anxiety disorder. J of Psychological Science. 2021; 20(105): 1587-1600.

URL: https://psychologicalscience.ir/article-1-1180-fa.html
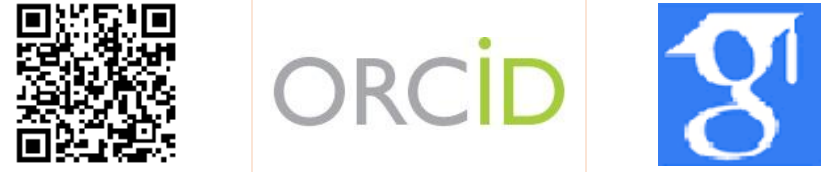

$\underline{10.52547 / J P S .20 .105 .1587}$
A R T I C L E I N F O

A B S T R A C T

Keywords:
Adolescents,
Mother - Child
Interaction,
Social Anxiety,
Social - Cognitive
Treatment

Received: 12 Mar 2021

Accepted: 18 Apr 2021

Available: 22 Nov 2021
Background: Various studies have shown the effect of Adler's cognitive-social program on parents or children and adolescents in order to reduce adolescent anxiety and improve parent-child interactions. But many of these Adlerian cognitive-social therapies have applied only limited aspects of the theory. In addition, these therapies have been performed only on children and adolescents or only on parents, and research conducted simultaneously by both parent and child. There is no embrace for him.

Aims: The aim of this study was the effectiveness of Adler cognitive-social education on the interaction of mothers and adolescents with social anxiety disorder.

Methods: This study was a quasi-experimental applied research with a pretest-posttest design with a control group. The statistical population of this study included adolescents 13 to 15 years old with social anxiety disorder and their mothers who had a file in Avae Ghasedak Clinic in District 5 of Tehran in 1398. By available sampling method, 32 mothers and adolescents were identified and Randomly assigned to experimental and control groups (16 experimental and 16 control). The instrument used in this study was the Parent-Child Relationship Scale (Mother Form) (Mark E. Fine, Morland and Undershobel, 1983), which was completed by adolescents before, after, and one month after. Adolescents and mothers in the experimental group participated in 12 sessions (eight sessions with adolescents and one sessions with mothers and three sessions adolescents and mothers) in the completed Adler program. Data were analyzed using mixed analysis of variance.

Results: The results showed that mother-child interactions (positive emotion, annoyance, replication, communication) in the experimental group after the intervention compared with the control group significantly increased $(\mathrm{p}<0.01)$. This means that in the profiles of the groups Experiment and control There is a difference between pre-test, post-test and follow-up stages.

Conclusion: Considering the effectiveness of Adler's social cognitive program on adolescents with social anxiety as well as improving the mother-child relationship, more extensive research is needed with more examples on the family and children and adolescents.

* Corresponding Author: Tahereh Najafi Fard, Ph.D Student of Psychology and Exceptional Children Education, Allameh Tabataba'i University, Tehran, Iran.

E-mail: njffrd64@yahoo.com

Tel: (+98) 9393033467

2476-5740/ (C) 2021 The Authors. This is an open access article under the CC BY-NC-ND license

(https://creativecommons.org/licenses/by-nc/4.0/). 


\section{Extended Abstract}

\section{Introduction}

Social anxiety disorder, categorized as one of the anxiety disorders, is defined as the fear of social and functional situations (Mohammadzadeh et al, 2020) and its prevalence among adolescents is reported from 19 to 33 percent (Esterahan, reported by Hasani et al, 2013). Furthermore, 20 percent of the children who are diagnosed with social anxiety, will develop severe problems as approaching the age of 16 (Hudson \& Rapee, 2015). Bowlby (1969) concluded that the lack of secure attachment figure for child will result in social anxiety. Additionally, negative parentchild interactions will consequence in anxiety disorders during adulthood (Ioffe et al, 2020; Bradford et al, 2017). Adolescents with secure attachment figure, on the other hand, are certain about their parents` availability and they will demonstrate lower levels of social anxiety in the future. Insecure attachment has direct correlation with specific anxieties, such as school anxiety (Bar-Haim et al, 2007), separation anxiety and social anxiety (Kerns et al, 2011). Adolescents who has developed insecure attachment style, are unable to solve social conflicts or build up friendship (Vagos \& Carvalhais, 2020); the social support received by their peers and caregivers is lower than adolescents with secure attachment style (Zerach \& Elklit, 2020) and this insecure attachment style leads to negative parentchild interactions as well as lower levels of selfregulation and self-control, conditions under which result in social anxiety (Colonnesi et. all, 2011). Despite Bowlby, Adler puts more emphasis on social concepts and states problematic child does not have four necessary features (connected: being safe, capability: being responsible, Count: being significant, courage: controlling difficult situations and overcoming fear) (Mahmoodian et al, 2018). Need gratification is a process in which environment plays a pivotal role, consequently, based on Adler's theory parent-child interaction and child`s social context are determining factors in either soothing or evoking children and adolescents` problematic behaviors. His emphasis on individual social context and a person connection to it based on social interest factor, in his theory is noticeable (Khabbaz et. all, 2016). As a result, with regards to the mental health of adolescents who are diagnosed with social anxiety and the growing number of them as well as limited Adlerian cognitive and social therapies using Adler`s theory concept narrowly and the lack of available researches through which the effectiveness of the mentioned method evaluated either parents or adolescents not both of them concurrently and dearth of surveys in which adolescents were the target group, this study`s goal is to answer the following question: "is Adler Cognitive-Social Education program effective for mother-adolescent interaction in adolescents diagnosed with social anxiety?"

\section{Method}

In this quasi-experimental study, pretest, posttest and follow-up (one month) are used. The statistical society included 13 to 15 year-old adolescents with social anxiety and their mothers who had been referred to Avaye Ghasedak clinic located in district 5 in Tehran in 1397. Available sampling was used to gather 32 participants (16 participants were categorized in experiment group and the other half was subjected in control group). Having permission from Allameh Tbabtabai University for licensed clinics in district 5 in Tehran, the mentioned Clinic was selected based on available sampling. Following that, briefing was held for clinic's managers, then, regarding entry and exit criteria, a sample including adolescents with social anxiety and their mothers was chose. After that, importance and goals of the present study were described for adolescents and their mothers and they were asked to sign a written consent for participating in this study. Having answered to parent-child relationship scale, participants were randomly divided into control and experiment group. The experiment group participants took part in a 12session cognitive- social educational program for anxiety disorder; at the end of the last session and a month later the mentioned scale was answered by the adolescents of both control and experiment groups. To analyze quantitative data, descriptive statistical methods, such as mean, standard deviation and ratio as well as mixed analysis of variance were utilized with the help of SPSS-23 software. Parent-child relationship scale was utilized in the present study. 


\section{Monthly Journal of Psychological Science}

The Alpha coefficient for this scale is 0.89 to 0.94 for father's subscales, general Alpha is 0.96, and for mother's subscales it is 0.61 to 0.94 with general Alpha of 0.96 which shows great internal consistency. Studies conducted in Iran confirmed the validity and reliability of this scale. Parhizgar (2002) concluded that reliability coefficients for father`s questionnaire is 0.93 and for mother`s questionnaire is 0.92 which indicates appropriate level of consistency (Heydarnia \& Charkhian, 2007).

\section{Results}

Based on the follow-up test utilized in the present study, mixed analysis of variance was employed to assess the influence of experiment on dependent variables. Normal distribution conditions including scores distribution, homogeneity of variances, linearity and sphericity were examined. The result of Mocheli sphericity test indicated that this hypothesis is acceptable ( $p>0.01)$. Moreover, the hypothesis of same regression line slope was confirmed $(\mathrm{p}>0.05)$. In order to evaluate normal distribution of variables Shapiro-Wilk test was utilized, based on which
Vol. 20, No. 105, Autumn(December) 2021

mother-child interaction subscales are normal ( $>0.05)$. The hypothesis of homogeneity of group variances was assessed by Levine test in three steps including pretest, posttest and follow-up and based on which the result was statistically insignificant ( $p$ > 0.01 ) and it can be concluded that the reiterated hypothesis is acceptable. The outcome indicated in table 1 demonstrates that all of the variables variations are statistically significant which points out that the mean in all three steps, pretest, posttest and follow-up is statistically significant. In addition, the comparison of two measurement steps in time variable illustrates that the difference between pretest and posttest as well as posttest and follow-up comparison of mother-child interaction variable was statistically significant.

With regards to table 1, Intragroup and intergroup mixed variance analysis shows that the change in all variables as a result of intragroup impact is statistically significant. In other words, group`s means`alterations during pretest, posttest and followup are statistically significant.

Table 1. Intragroup and intergroup mixed variance analysis for mother-child interaction variable

\begin{tabular}{cccccccc}
\hline Variable & Source of change & SS & DF & SM & F & p & Effect size \\
\hline \multirow{3}{*}{ Positive emotion } & Time & 4959.81 & 2 & 2479.90 & 91.12 & 0.01 & 0.75 \\
& group & 268.78 & 1 & 268.78 & 66.09 & 0.01 & 0.69 \\
& Group * Time & 3306.06 & 2 & 1653.03 & 60.75 & 0.01 & 0.67 \\
Annoyance & Time & $72 / 56$ & 2 & 36.28 & 16.75 & 0.01 & 0.69 \\
& group & 66.12 & 1 & 66.12 & 61.38 & 0.01 & 0.67 \\
& Group * Time & 18.18 & 2 & 9.09 & 4.20 & 0.02 & 0.24 \\
Replication & Time & 21.93 & 2 & 10.97 & 9.33 & 0.01 & 0.43 \\
& group & 5.83 & 1 & 5.83 & 2.31 & 0.13 & 0.07 \\
& Group * Time & 27.52 & 2 & 13.76 & 11.70 & 0.01 & 0.38 \\
Relationship & Time & 914.65 & 2 & 457.32 & 47.36 & 0.01 & 0.61 \\
& group & 282.03 & 1 & 282.03 & 42.75 & 0.01 & 0.59 \\
& Group * Time & 512.68 & 2 & 256.35 & 26.55 & 0.01 & 0.56 \\
\hline
\end{tabular}

\section{Conclusion}

The result of the present study illustrated that Adler Cognitive-Social Education consequenced in better mother- child interaction and its influence lasted until follow-up session. These outcomes are consistent with Rostami et all, 2019; Bettner, 2020; Cooley et all, 2014; Foster et all; findings.

Elaborating the results, the impact of this approach on parent-child interaction and adolescent 's response is noticeable. It is indicated that the presence of a parent/parents during the educational program made it more effective (Abbasi \& Neshatdoost, 2013). Mother`s engagement during the program can affect their interaction with their teen and this will improve their interaction quality. Explaining the problemsolving skill in this program for mothers, elevated their flexibility when they encountered the adolescent's obstacle and they could help him to solve his problem; the process through which motherchild interaction enhanced (Dillman Taylor et all, 2019). Furthermore, it is worth mentioning that 
adolescents were present during the program and notable parts of the session were dedicated to them. the literature of the present study illustrates that adolescents were not involved during the program and their parents were the target group, however, in the present study both adolescents and their mothers were present and this lead to better interaction (positive affects increased, reduced annoyance, better communication and identification).

Elaborating this finding, problem-solving is a skill that helps adolescents to think divergently and be more flexible, write various solutions and finally, select the best one. Furthermore, during this program courage was reinforced, thus, the adolescents became more confident, self-controlled, self-accepted and others-accepted as well as the awareness gained about dysfunctional patterns by which he could change this pattern (Akay \& Bratton, 2017). Another notable finding that can be mentioned and has not been illustrated in other surveys, is stressful situation simulation primary in an imaginary situation in clinic, then, a real-life situation in which adolescents could practice the learned coping skills which resulted in lower levels of anxiety experienced by them which positively impacted parent-child interaction.

\section{Ethical Considerations}

Compliance with ethical guidelines: The authors extracted this article from the $\mathrm{PhD}$ dissertation of the first author, which approved under No 365 date, 27.2.2017 in the Faculty of Psychology, Allameh Tabataba'i University, Tehran. Obeying ethical rules, a written consent is obtained from participants during pretest, posttest and follow-up. Additionally, participants were given the assurance that either their personal or clinical information would not be published without their persmission. Funding: This study was conducted as a $\mathrm{PhD}$ thesis with no financial support.

Authors' contribution: The first author was the senior author, the second were the supervisors and the third and forth was the advisors.

Conflict of interest: the authors declare no conflict of interest for this study.

Acknowledgments: I would like to appreciate the supervisor, the advisors, the parents and participants in the study. 


\section{اثربخشى آموزش شناختى - اجتماعى آدلر بر تعامل مادران و نوجوانان داراى اختلال اضطراب اجتماعى}

\section{طاهره نجفىفرد" '، حميد عليز اده'، احمد بر جعلى"، محمد عسكرى}

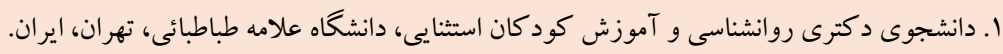

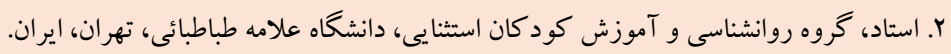

r. استاد، گروه روانشناسى، دانشكاه علامه طباطبائى، تهران، ايران.

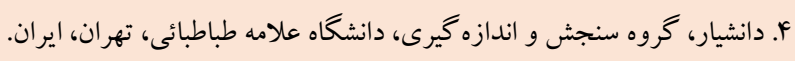

\section{جكيده}

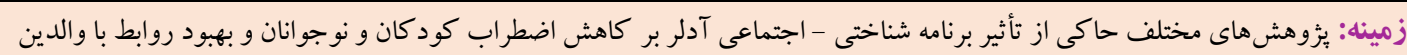

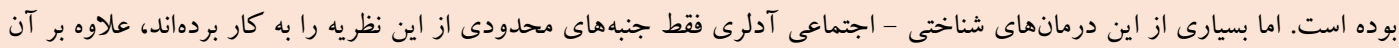

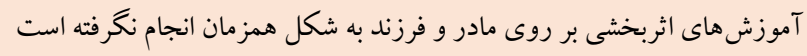

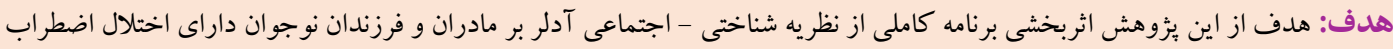

اجتماعى بود.

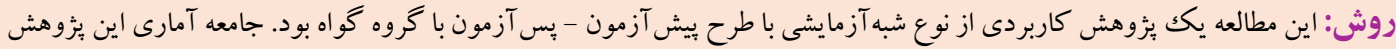

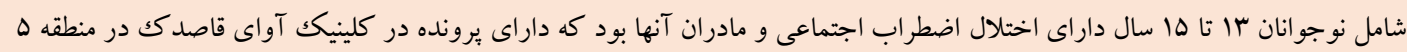

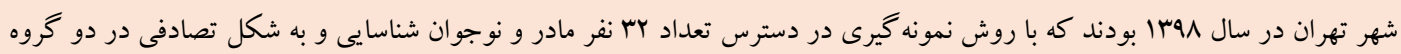

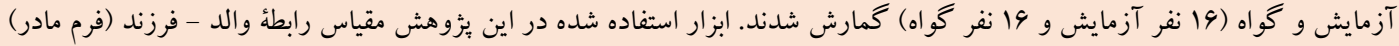

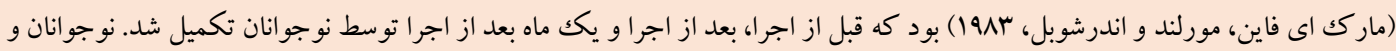

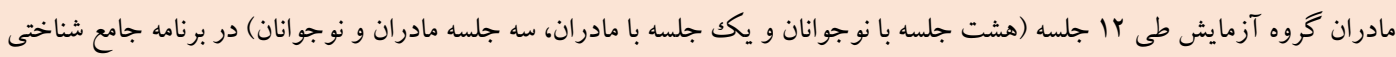

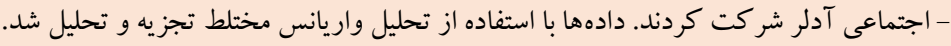

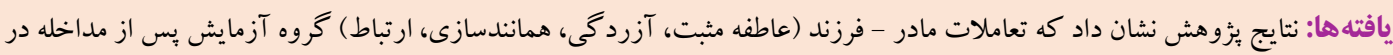

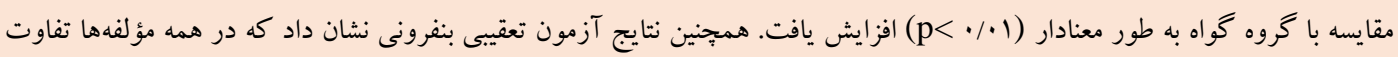

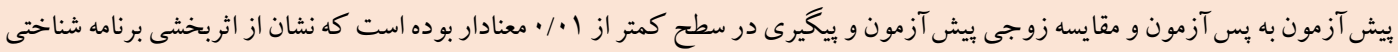

$$
\text { اجتماعى آدلرى در طى زمان دارد. }
$$

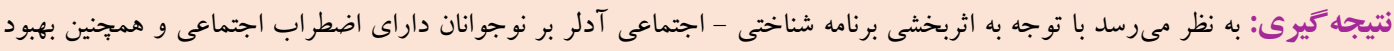

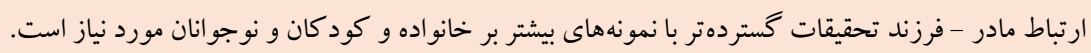

مشخصات مقاله

كليدوازهها:

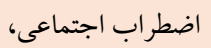

تعاملات مادر - فرزند،

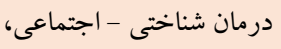

نوجوانان

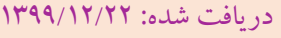

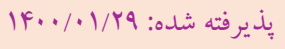

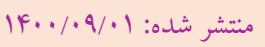

* نويسنده مسئول: طاهره نجفىفرد، دانشجوى دكترى روانشناسى و آموزش كود كان استنايى، دانشكاه علامه طباطبائى، تهران، ايران.

رايانامه: njffrd64@yahoo.com

تلفن: 
است رابطه ميان والد و فرزندان و بافت اجتماعى فرزند عاملى مؤثر در

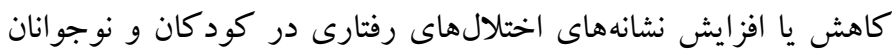

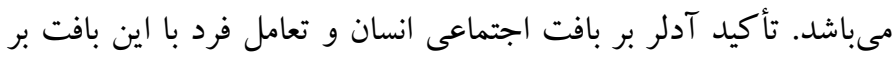

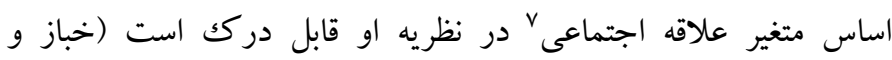

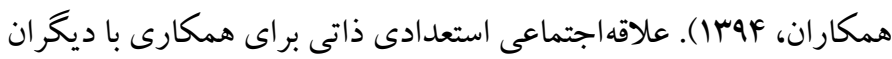
جهت رسيدن به اهداف شخصى و اجتماعى است كه از طريق تجارب يادگيرى در دوره كودكى رشد مى كند. آدلر معتقد است كه علاقه

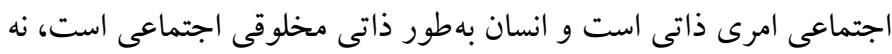

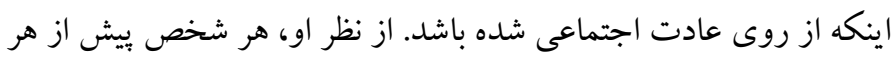

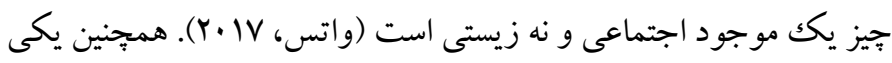

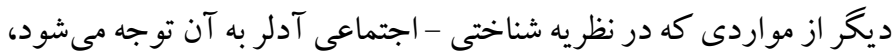

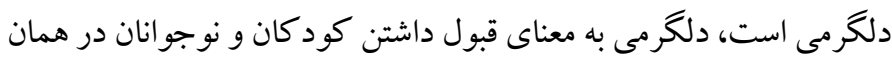

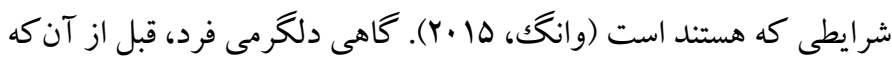

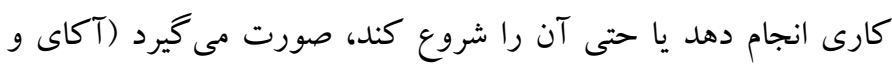

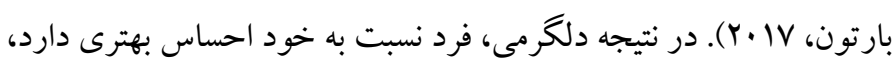

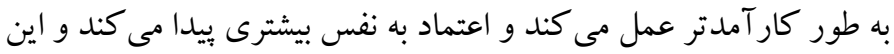

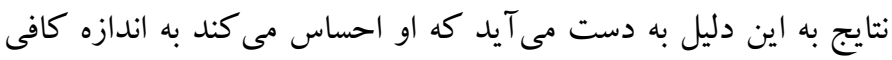

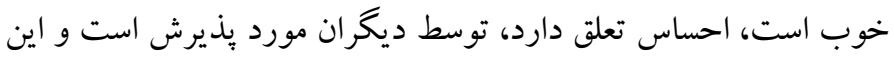

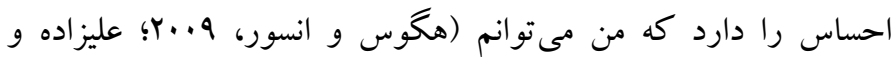

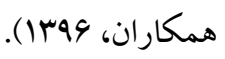

همجِنين آدلر به اهميت منظومه خانو اده بر شكل گيرى شخصيت كود كان

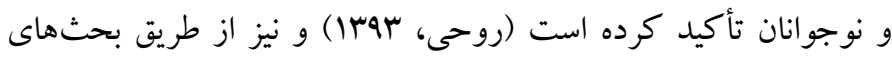

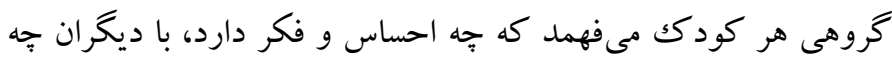

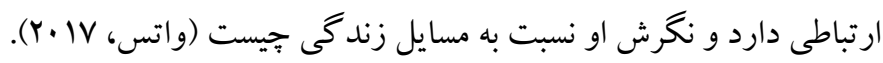

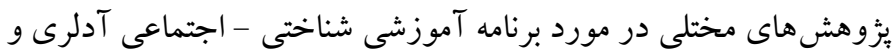

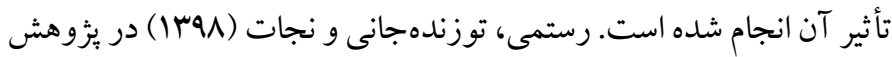
خود شيوه آدلر - درايكورس را بر كيفيت رابطه والد - كودك در كود كان

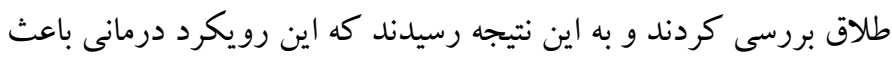

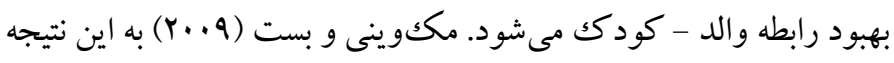

${ }^{5}$. Count

${ }^{6}$. Courage

${ }^{7}$. social intrest
مقاله

يكى از انواع اختلالهاى اضطرابى، اختلال اضطراب اجتماعى، ترس از

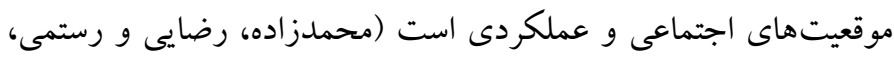

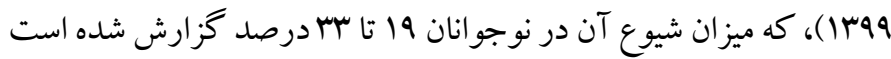

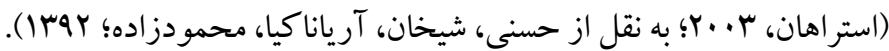

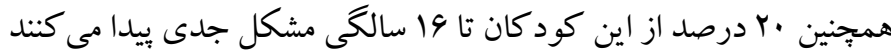

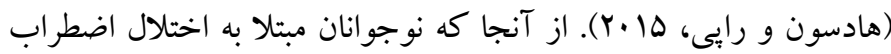

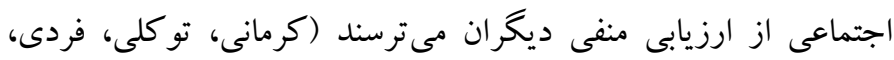

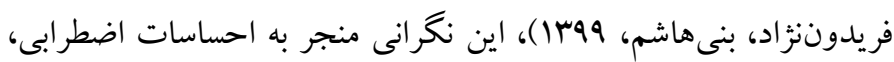

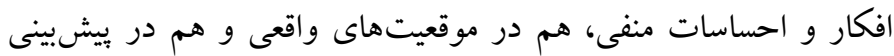

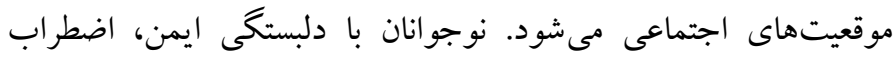

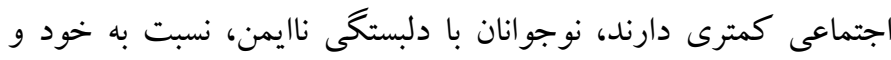

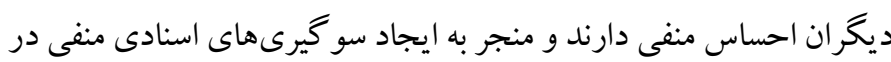
آنها مىشود و باعث مىشود اين نوجوانان اضطراب زيادى را در موقعيت

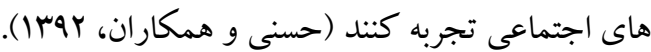
به نظر مىرسد بيشتر علت شناختى در كود كان بر نقش دلبستكى ' كود كان هان

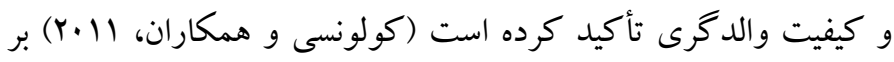
اساس مطالعات بالبى (1999) غياب بايگاه امن بر ایى كود كك منجر به ايجاد اضطراب اجتماعى در وى مىشود. همجنين تجربه مكرر كودكك از

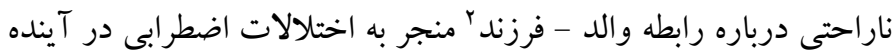

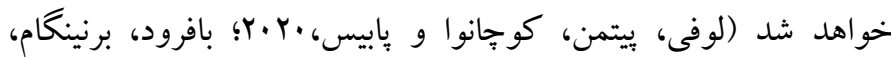

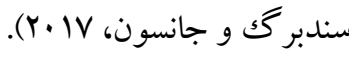
اما آدلر بر مفاهيم اجتماعى بيشترى تاكيد دارد، در نظريه آدلر (عليزاده،

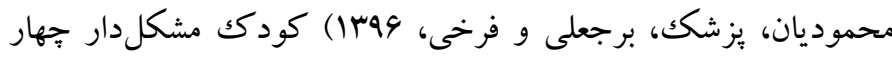
ويزگى ضرورى (احساس تعلق"': داشتن احساس امنيت، احساس تو انمندى": احساس داشتن صلاحيت و مسئوليت پِيرى، احساس به حساب آمدنه: احساس مهم بودن و متفاوت بودن و دلكرمى": كنترل كردن

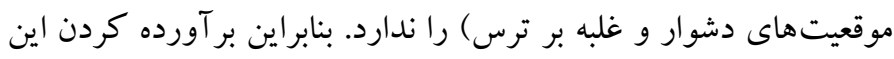
نيازها به كيفيت محيطى كه فرد در آن رشد مى كند وابسته است، آدلر معتقد

${ }^{1}$. attachment style

2. Parent- child relation

3 . Connected

4. Capable 
يُزوهش حاضر. همجنين ملاككهاى ورود به بُزوهش براى مادران شامل

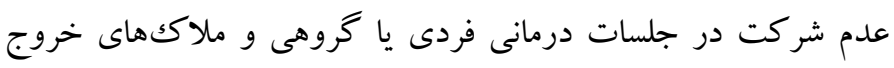
مادران شامل داشتن بيمارى يا ناتوانى خاص.

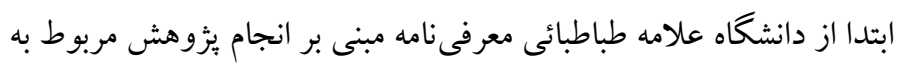

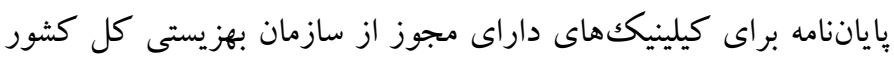

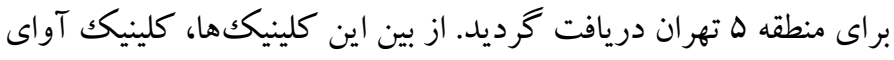
قاصدك (به صورت در دسترس) انتخاب شد. يس از ورود به كلينيك ديك

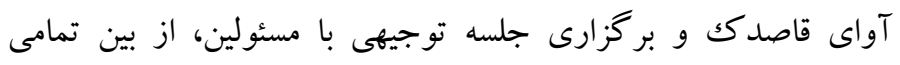

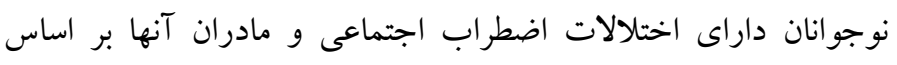
ملاكك هاى ورود و خروج، نمونه انتخاب شد و با ذكر ضرورت و اهداف يُزوهش براى اين نوجوانان، از آنان و والدين آنها رضايتنامه كتبى مبنى بر شركت در بزوهش اخذ شد. مقياس رابطه ولى - فرزندى تكميل شد،

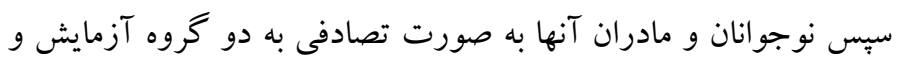

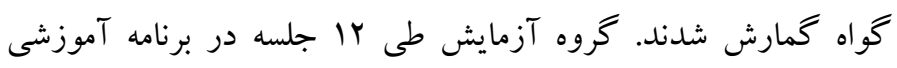
شناختى - اجتماعى اختلال هاى اضطرابى شر كت كردند. جلسات آموزشى درى دو روز در هفته و به مدت شش هفته انجام شد. برنامه آموزشى در تاريخ

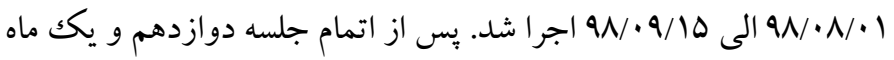
بِ از آن يرسشنامه مجدداً توسط نوجوانان هر دو گروه تكميل شد. در

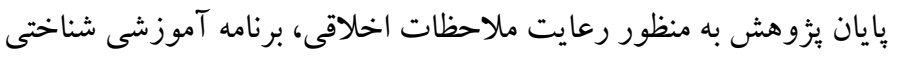

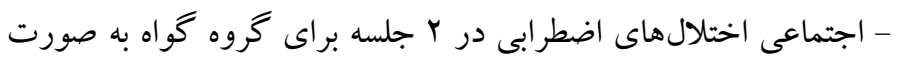

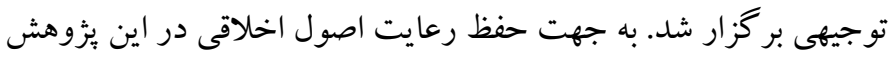
سعى شد تا جمع آورى اطلاعات در هر سه مرحله (ييش آزمون، يس آزمون

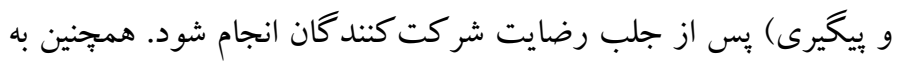
شركت كنند كان درباره رازدارى در حفظ اطلاعات شخصى و ارائه نتايج بدون قيد نام و مشخصات شناسنامه افراد، اطمينان داده شد. جهت تحليل دادهها از فنون آمار توصيفى مانند ميانگين، انحراف معيار و نسبت استفاده

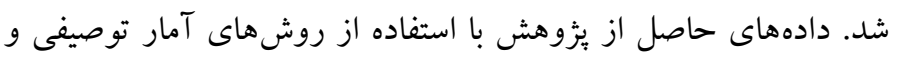

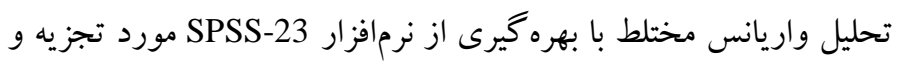

$$
\text { تحليل قرار خرفت. }
$$

دست يافتند كه آموزش والدين به شيوه آدلرى باعث تغييرات معنادار رفتارى و ارتباطى والد - كود كك مى شود. همجنين باهلمن و دينتر (1. (Y)

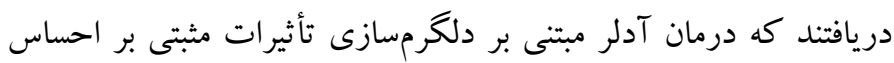

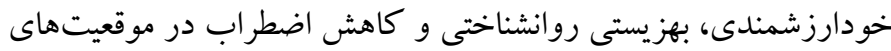

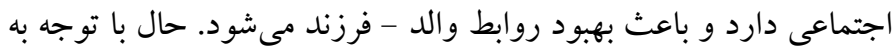

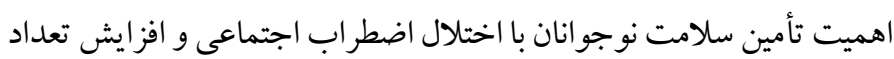
نوجو انانى كه داراى اختلال اضطراب اجتماعى هستند و با توجه به اينكه

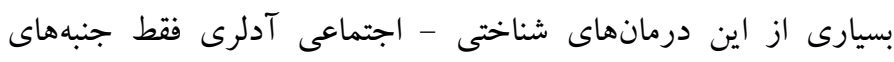

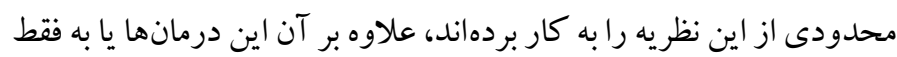

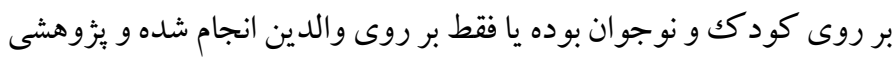

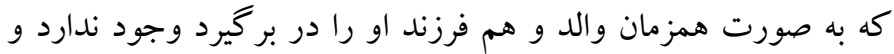

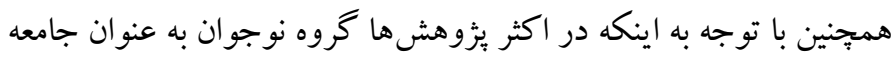

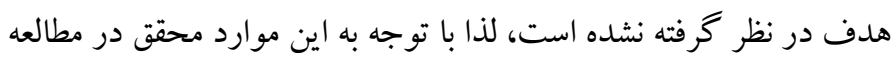

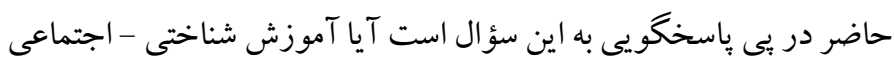

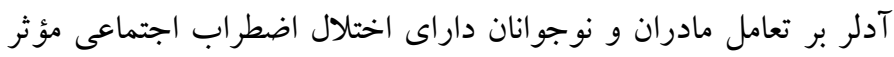

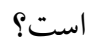

روش الف) طرح هؤوهش و شر كت كنند عان: در اين مطالعه شبه آزمايشى از

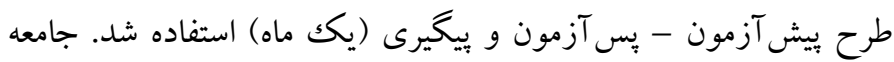

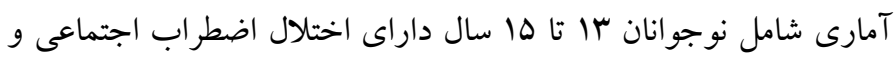
مادران آنها كه داراى برونده در كلينيك آواى قاصدكك در منطقه هـ شهر

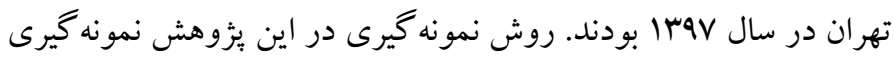

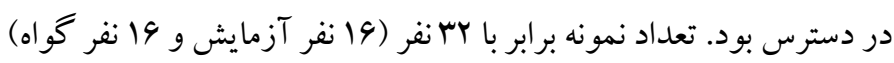

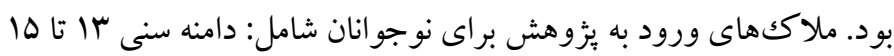

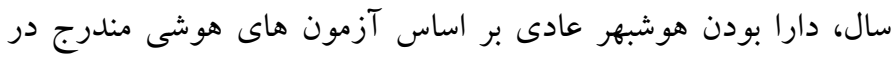

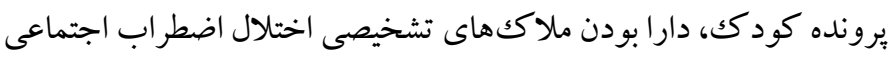

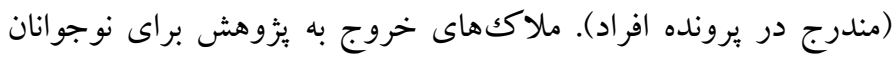

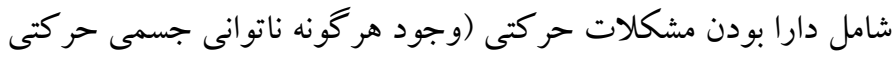
واضح در كودكى)، حسى (ناينايى، ناشنوايى)، اختلال رفتارى (اختلال رفتار هنجارى، اختلال رفتار مقابله ای) بر اساس درج در يرونده كود كان،

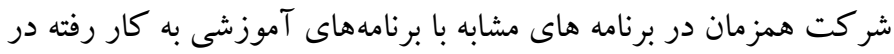


با توجه به اينكه در اين بزُوهش آزمون بيگيرى اجرا شده است، از تحليل

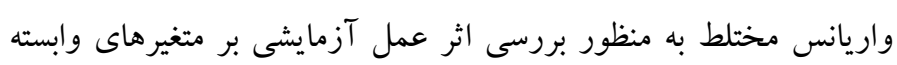

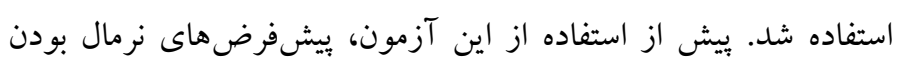

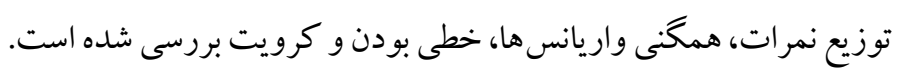

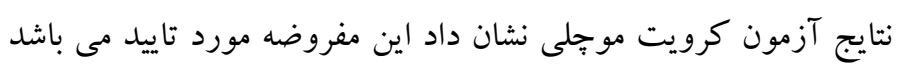

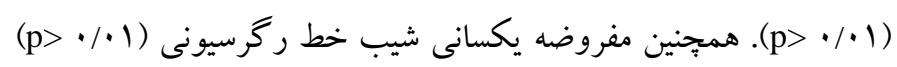

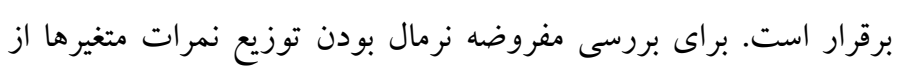

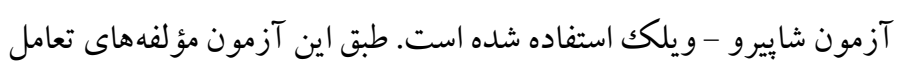

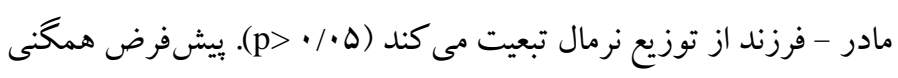

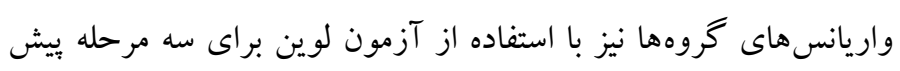

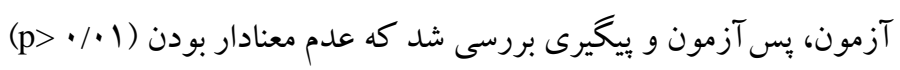

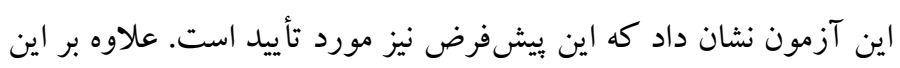

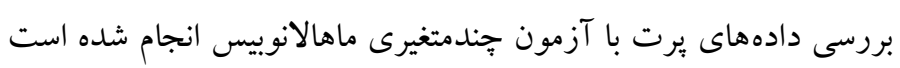

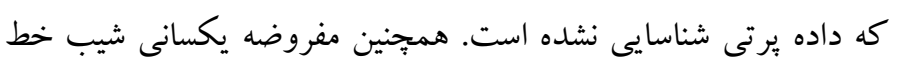

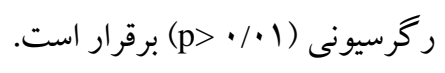

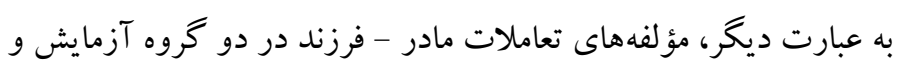

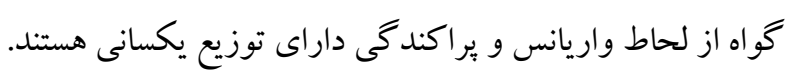

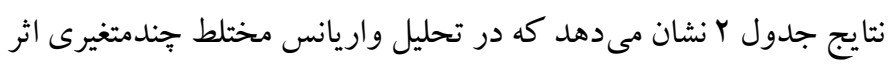
عامل گروه (

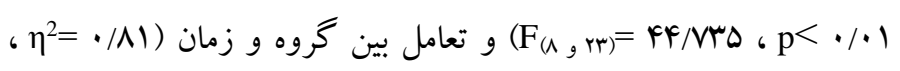

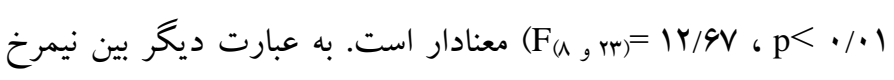

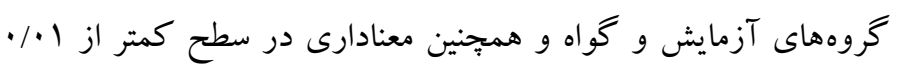

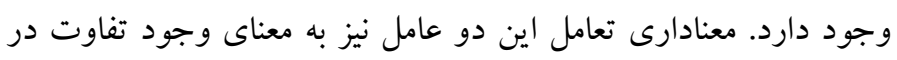

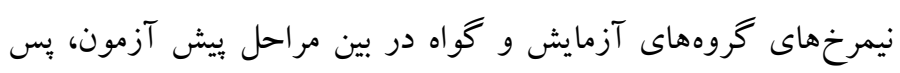
آزمون و بيخيرى است.

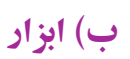
مقياس رابطه والد - فرزند' (PCRSM): مقياس رابطه ولى - فرزندى يكى اري

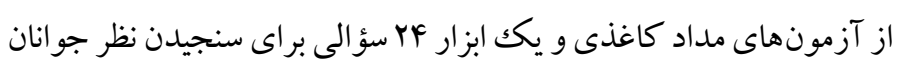

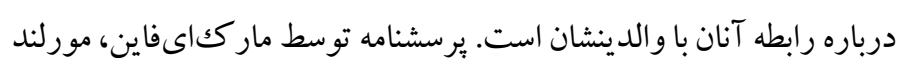
و اندرشوبل (به19) با هدف سنجيدن كيفيت رابطه ولى - فرزند تهيه شد.

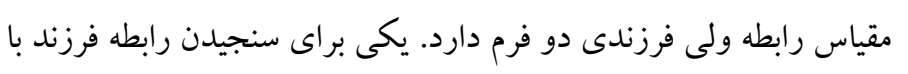

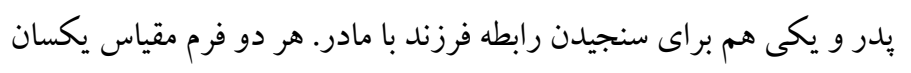

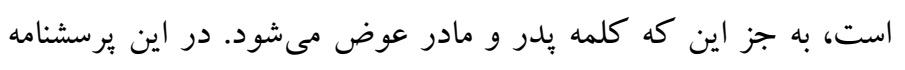

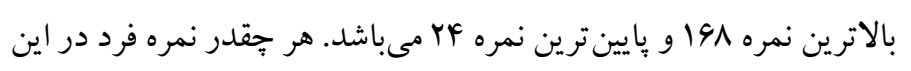

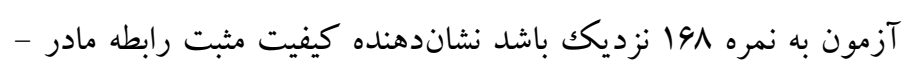
فرزند است و هر جقدر به نمره بF نزديكك باشد نشاندهنده كيفيت بِايين

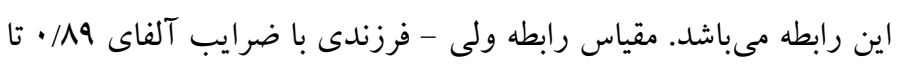

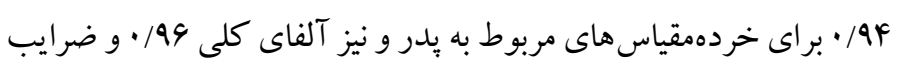

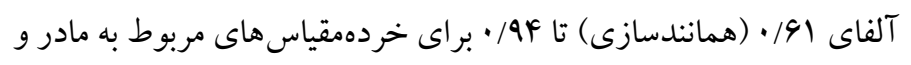

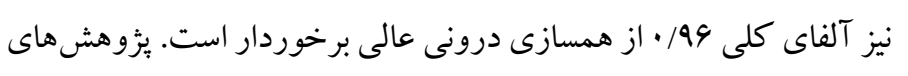

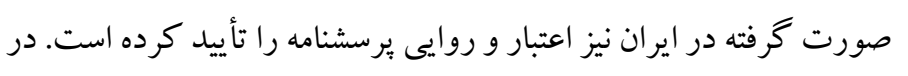

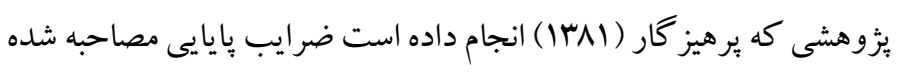

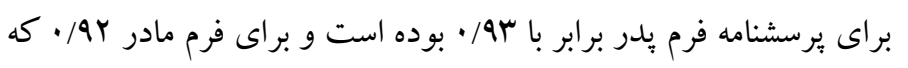

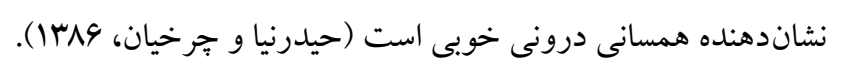
برنامه آموزشى شناختى - اجتماعى اختلال هاى اضطر ابى از برنامه شناختى - اجتماعى آدلر اقتباس شده است. در جدول ا خلاصه جلسات برنامه آموزشى شناختى - اجتماعى اختلال

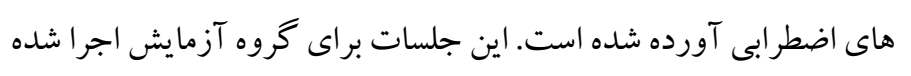
است.

\section{يافته ها}

از بين بr مادر شر كت كننده در اين يزوهش 19 مادر تحصيلات دييلم و

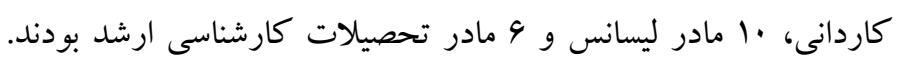

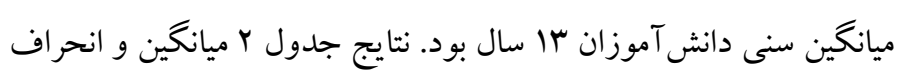
معيار متغيرهاى بزٔوهش را نشان مى دهد.

1. Parent - Child Relationship Survey: Mother 
جدول ا. خارجوب جلسههاى برنامه آموزشى شناختى - اجتماعى

\begin{tabular}{|c|c|c|c|}
\hline تكاليف & 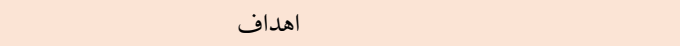 & محتوا & 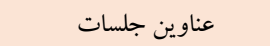 \\
\hline استفاده از تمرين شناخت يكديخر & 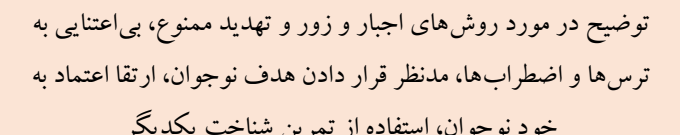 & ايجاد رابطه و اصلاح نغرش و & اول: مادران و نوجوانان \\
\hline استفاده از كاربر گك حل مسئله & 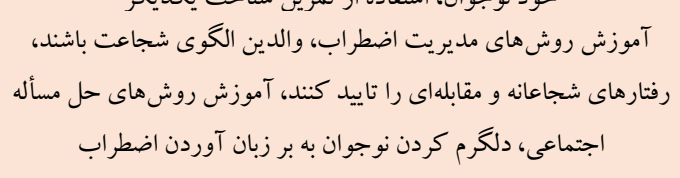 & مفاهيم آدلرى براى مديريت ارتباط & دوم: مادران و نوجوانان \\
\hline استفاده از كاربرك ثبت افكار و & مخفتخو در مورد احساسات و هيجانهاى مختلف و استفاده از روشهاى برى آموز هيجانهاى جسمى، شناسايى پياسخهاى جسمى به & آكاهى هيجانى و تله هاى فكرى & 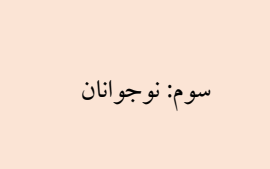 \\
\hline استفاده از كاربر كى فكر و احساس & 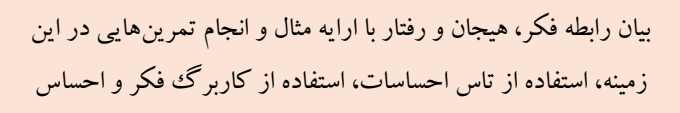 & آكاهى هيجانى و تلههاى فكرى & جهارم: نوجوانان \\
\hline تكنيك طنز و تكنيك قصد متناقضنما & 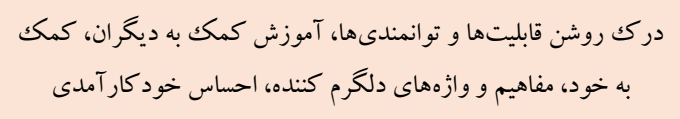 & دلخرمى - قابليتها & 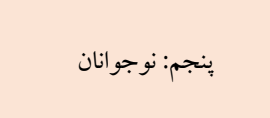 \\
\hline كشيدن نقاشى بر اساس تكنيك طورى & شجاعت ناكامل بودن، احساس برابرى، مديريت رفتار هاى خودشكن & دلخرمى - قابليتها & 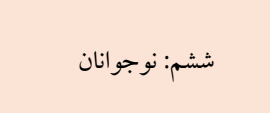 \\
\hline استفاده از كاربر گك حلمسئله & 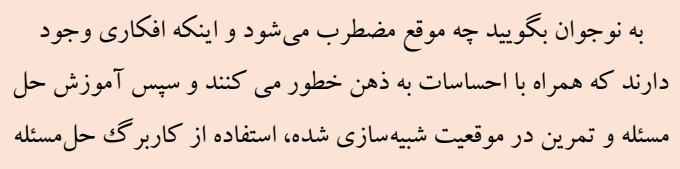 & خود گُويى و حل مسئله و شبيهازى & هفتم: نوجوانان \\
\hline 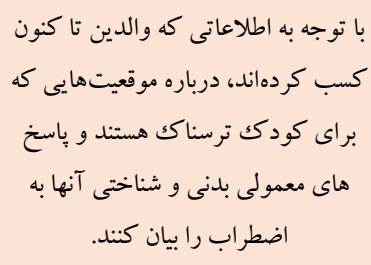 & جلسه با والدين و ياسخ به سؤالهاى آنها & دلغرمسازى والدين & 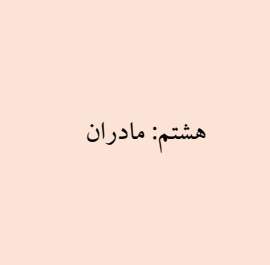 \\
\hline شبيه سازى در محيط كلينيك & در آين جلسه نوجوانان در معرض موقعيتهاى شبيه سازى شده اضطراب & شبيهسازى موقعيتهاى اضطر ابزا & ن أهم: نوجوانان \\
\hline بردن دانش آموز در موقعيت واقعى و نحوه رفتار او در آن موقعيت & در اين جلسه نوجوانان در معرض موقعيتهاى اضطر اب آور خفيف قرار & تجربه موقعيت اضطرابزا متوسط & 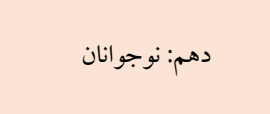 \\
\hline بردن دانش آموز در موقعيت واقعى و نحوه رفتار او در آن موقعيت & 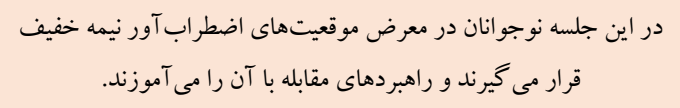 & تجربه موقعيت اضطرابزا شديد در & يازدهم: نوجوان \\
\hline & در اين جلسه موارد ذكر شده در جلسات بيشين مرور خو اهد شد. & مرور: دلكرمسازى و قابليتها & 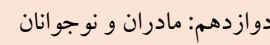 \\
\hline
\end{tabular}

وجود دارد، همجينين در مقايسهاى بين بِ بـآزون و بيخيرى تفاوت

$$
\text { معنادار بوده است. }
$$

در ادامه نتايج جدول ب گوياى آن است تغييرات كليه مؤلفهها معنادار است. به عبارت ديخر تغييرات ميانكين گروهها در مراحل مختلف بيش آزمون، يس آزمون و بيكيرى معنادار بوده است. همبجنين يافته هاى حاصل از مقايسه دو به دو مر احل اندازه گيرىها در عامل زمان نشان مى دهد كه در مولفههاى تعاملات مادر - فرزند روانى بين بيش آزمون و يس آزمون تفاوت معنادارى 
مطابق جدول بانتايج تحليل واريانس مختلط براى منابع اثر درون گروهى و

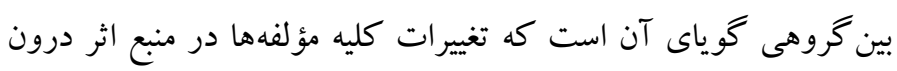
گروهى معنادار است. به عبارت ديخر تغييرات ميانخين گرووهها در مراحل

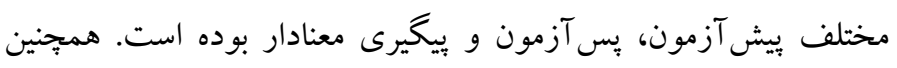

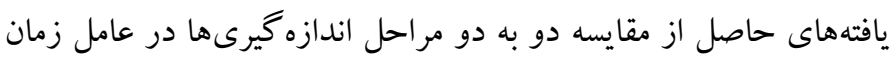

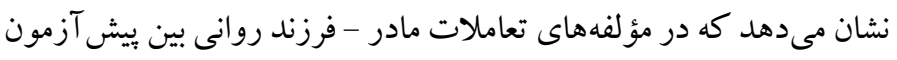
و پِ آزمون تفاوت معنادارى وجود دارد، همجينين در مقايسهاى مهاى بين

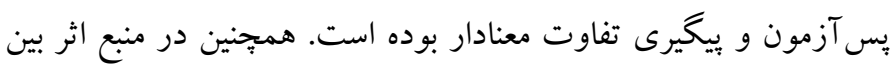

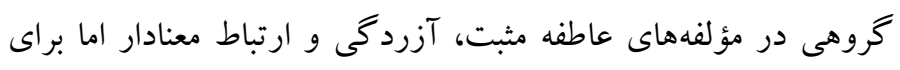

$$
\text { همانندسازى معنادار نبود. }
$$

نتايج مقايسه زوجى حاصل از آزمون تعقيبى بنفرونى نشان مى دهد كه در

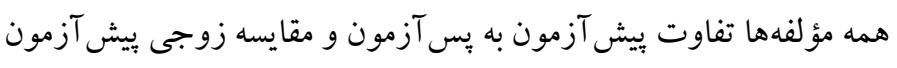

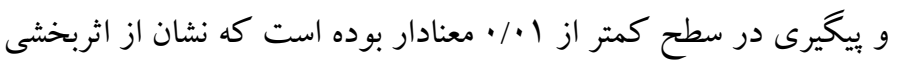

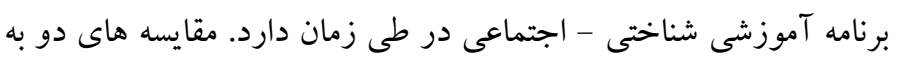

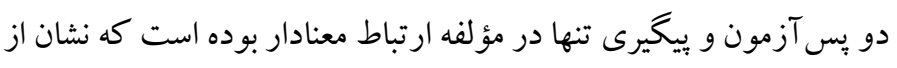
آن دارد كه اثر آموزش بر اين مؤلفه ادامه داشته است.

\begin{tabular}{|c|c|c|c|c|}
\hline انحراف معيار & ميانگين & كروه & مرحله & مولفه \\
\hline$V / V \Delta$ & FG/AV & آزمايش & يِيش آزمون & عاطفه مثبت \\
\hline $1 / 4 q$ & $F \Delta / .9$ & كواه & & \\
\hline $9 / 19$ & $\mathrm{~V} 9 / .$. & آزمايش & پֶ آزمون & \\
\hline$\Lambda / \Lambda I$ & FV/AV & كو اه & & \\
\hline$\Delta / I Y$ & VY/AV & آزمايش & يِيخيرى & \\
\hline $1 . / 19$ & fa/or & كو اه & & \\
\hline $1 / 94$ & N/9Y & آزمايش & يِيش آزمون & آزردگى \\
\hline $1 / v$ & $1 \cdot / \pi 1$ & كواه & & \\
\hline$Y / \Delta F$ & $0 / 90$ & آزمايش & يس آزمون & \\
\hline $1 / r Y$ & $9 / \Gamma T$ & كو اه & & \\
\hline س & $9 / 11$ & آزمايش & ييخيرى & \\
\hline$r / T r$ & $\Lambda / Y \Delta$ & كو اه & & \\
\hline $1 / 01$ & $9 / 11$ & آزمايش & يِيش آزمون & همانندسازى \\
\hline 1/VQ & $1 \cdot / 4 r$ & كواه & & \\
\hline $1 / r V$ & $|r /| \Lambda$ & آزمايش & يس آزمون & \\
\hline$r / M$ & $1 \cdot / 41$ & كواه & & \\
\hline I/VF & $11 / 9 r$ & آزمايش & بيخيرى & \\
\hline$r / Y \Lambda$ & $9 / 9 \Delta$ & كواه & & \\
\hline$F / F Y$ & $r \cdot / \Delta$. & آزمايش & يِيش آزمون & ارتباط \\
\hline$F / F \Delta$ & $r \cdot / A V$ & كو اه & & \\
\hline$r / 4$. & $\pi / \Delta$. & آزمايش & يس آزمون & \\
\hline$r / 94$ & rY/QT & كواه & & \\
\hline $1 / 99$ & $r V / 9 \Lambda$ & آزمايش & ييخيرى & \\
\hline$r / l r$ & $r .1 .4$ & كواه & & \\
\hline
\end{tabular}

جدول ". نتايج تحليل واريانس مختلط درون كروهى و بين تروهى براى مؤلفهاى تعاملات مادر - فرزند

\begin{tabular}{|c|c|c|c|c|c|c|c|}
\hline ضريب اتا & $\mathrm{P}$ & F & ميانگين مجذورات & درجهآزادى & مجموع مجذورات & منبع تغيير & متغير \\
\hline$\cdot / V \Delta$ &.$/ 1$ & $91 / 14$ & YFVQ/q. & $r$ & $F 9 \Delta ৭ / \wedge 1$ & زمان & \\
\hline$\cdot / 99$ &.$/ 1$ & 991.9 & YGAY/VA & 1 & rGAYTVA & كروه & عاطفه مثبت \\
\hline$\cdot 19 \mathrm{~V}$ &.$/ 1$ & 4. $/ v \Delta$ & $190 r / \cdot r$ & r & $\mathrm{rr} .91 .9$ & كروهـ"زمان & \\
\hline .199 &.$/ 1$ & 19/VD & rG/rA & r & $V Y / D Q$ & زمان & \\
\hline $.19 \mathrm{~V}$ &.$/ \cdot 1$ & $91 / \% 1$ & $99 / 1 r$ & 1 & $99 / 1 \mathrm{r}$ & كروه & آزردمى \\
\hline$\cdot / T F$ & $\%$ & $f / r$. & $9 / \cdot 9$ & r & $\mid N / 1 \Lambda$ & كروهُزمان & \\
\hline$\cdot / 4 \pi$ &.$/ \cdot 1$ & $9 / \pi$ & $1 . / 9 \mathrm{~V}$ & r & $r \mid q T$ & زمان & \\
\hline$\cdot / \cdot v$ & 要 & T/T & $\Delta / \Lambda \mu$ & 1 & $\Delta / \wedge \Gamma$ & كروه & هماندسازى \\
\hline$\cdot /$ / &.$/ 1$ & $11 / \mathrm{v}$ & Ir/VG & r & rV/DT & كروهـزمان & \\
\hline .191 &.$/ \cdot 1$ & FV/rq & FOV/RT & r & $9 / 4 / 90$ & زمان & \\
\hline.$/ 09$ &.$/ \cdot 1$ & FY/VD & $r \wedge Y / \cdot r$ & 1 & $r A Y / \cdot r$ & خروه & ارتباط \\
\hline .109 &.$/ \cdot 1$ & YQ/DD & rDG/ND & r & $\Delta 1 Y / 9 \Lambda$ & گروهه*زمان & \\
\hline
\end{tabular}


جدول ع. نتايج آزمون تععقيب بنفرونى براى مقايسه زوجى سطوح زمانى سنى

\begin{tabular}{|c|c|c|c|c|}
\hline Sig & تفاوت ميانگين & سطح II & سطح I & متغير \\
\hline.$/ \cdot 1$ & $-10 / 99$ & ֵֶ آزمون & يِش آزمون & \\
\hline.$/ \cdot 1$ & $-|f / q|$ & يِيخيرى & يِيش آزمون & عاطفه مثبت \\
\hline .1 .4 & $1 / \Delta 9$ & ييخيرى & يس آزمون & \\
\hline $.1 \cdot 1$ & $1 / 9 V$ & پِ آزمون & ييش آزمون & \\
\hline.$/ \cdot 1$ & $1 / 99$ & بيخيرى & بيش آزمون & آزرد گى \\
\hline$\cdot / 99$ & $-\cdot / T \Lambda$ & ييخيرى & يس آزمون & \\
\hline .1 .1 & $-1 / 1 r$ & ״ֶ آزمون & يّش آزمون & \\
\hline.$/ \cdot r$ & $-\cdot / \Lambda \Delta$ & يِيخيرى & ييش آزمون & همانندى \\
\hline .190 & $\cdot / Y \Lambda$ & ييخيرى & ״ֶ آزمون & \\
\hline.$/ \cdot 1$ & $-V / \Delta r$ & קֵس آزمون & ييش آزمون & \\
\hline $.1 \cdot 1$ & $-r / 19$ & ييخيرى & يِيش آزمون & ارتباط \\
\hline $.1 \cdot 1$ & F/ro & ييخيرى & يֶ آزمون & \\
\hline
\end{tabular}

باعث بهبود رابطه مادر - فرزند مىشود. به علاوه در جلسات كروهى با مادران بر اصول دلكرمسازى تأكيد مىشود و اين اصل جايكزين تنبيه و

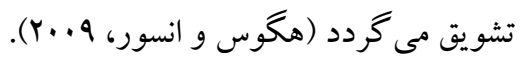
همجنين ماهيت كروهى اين آموزش براى والدين كه در اين يثروهش به كار كر فته شد، خود باعث شد مادران از تجربههاى يكديخر استفاده نمايند. زير ا والدين فرصتى بر اى ابراز نقطهنظر ها و نخر انى هايشان دارند و مى توانند مشكلاتى كه با كودكك دارند را مطرح نمايند، در اين جلسات والدين مى آموزند كه نوجوانان راطورى تربيت كنند كه آماده انجام تكاليف زندكى باشند و با خود و ديكران كنار آيند و روابط سالم و صميمى داشته باشند، و نيز احتر ام متقابل رادر ارتباط بانوجوانان حفظ كنند (كاراياكيز، آكتان، كاراياگيز، ·r.r.r). بنابراين به والدين آموزش داده مىشود كه به جاى رويكردهاى تشويقى كه وجود دارد بر دلكرمى تأكيد كنند، به جاى اطاعت برورش همكارى و تشريك مساعى را به نوجوانان بياموزند و در نهايت به جاى استفاده از ياداش و تنبيه بر بيامدهاى طبيعى و منطقى تأكيد كنند در نتيجه اين امر باعث بهبود روابط مادر - فرزند شده است (واتس، IV) (Y). همجنين كفته شد كه در اين برنامه نوجوانان نيز شركت داشته و بخش اعظم جلسات با نوجوانان است. در ئزوهشهايى كه مطرح شد نوجوانان وارد مداخله آموزشى نمى شدند و فقط والدين آنها در اين آموزشها شركت مى كردند اما در اين آموزش نوجوانان و مادران آنها با هم در آموزش شركت كردند و همين امر باعث بهبود روابط والد - فرزند (بهبود عاطفه مثبت، كاهش آزردگى، همانندى و بهبود ارتباط) شد.

\section{بحث و نتيجه كيرى} نتايج يزوهش نشان داد كه برنامه آموزشى شناختى - اجتماعى اختلال الهاى اضطرابى منجر به بهبود تعاملات مادر - فرزند شده و اثر آن تا مرحله

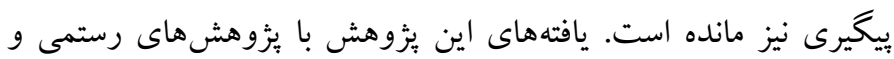

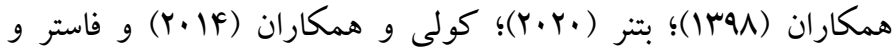

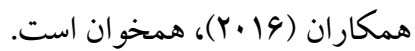
در تبيين اين يافته بايد به تأثير اين رويكرد بر ارتباط والد - فرزند و ونوع الثران

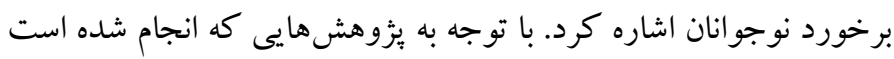

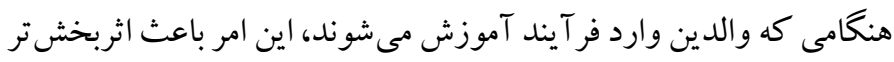

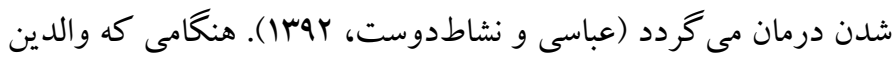

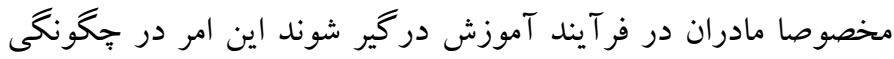

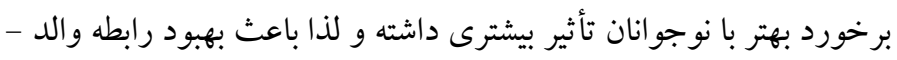

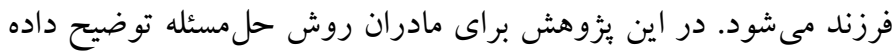

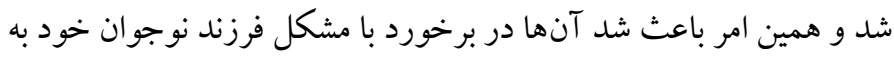

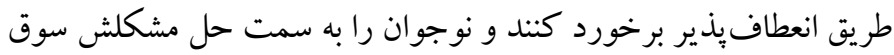
دهند و از همين طريق روابط مادر - فرزند بهبود يابد (دليمانتيلور و و

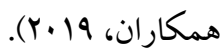
همجنين با آموزش به والدين مىتوان از مشكلات نوجوانان كاست، اين آنان برنامه نقشه راهى را در اختيار مادران قرار مىدهد، و به آنها آرامش فكر آنس

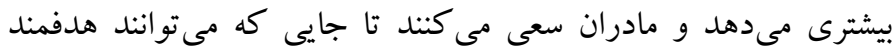

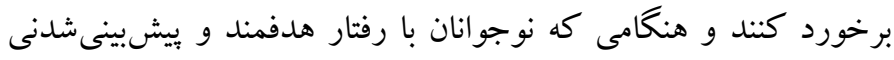

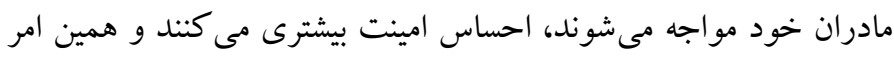


نوجو انان هيجانات خود رابه خوبى شناسايى كرده و همين امر باعث بهبود روابط آنها با مادرانشان شده است.

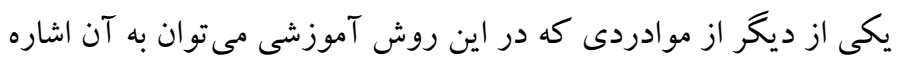

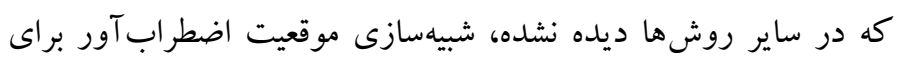

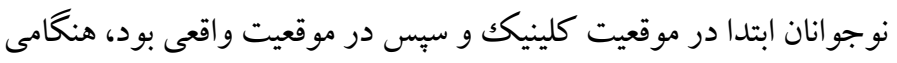

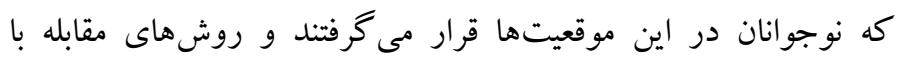

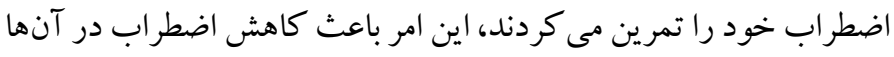
شد و هنگامى كه اضطراب آتها كاهش يافت اين امر باعث بهبود رابطه و الد - فرزند شد.

بثزوهش حاضر مانند هر مطالعه ديخرى داراى محدويتهايى مانند محدود

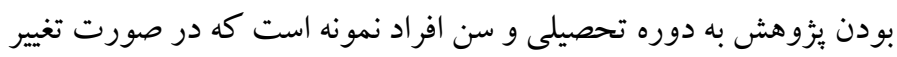

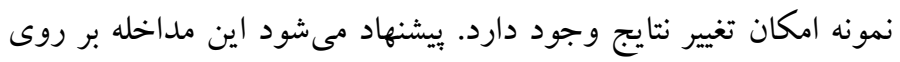

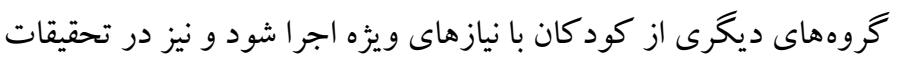
آينده از تعداد بيشترى آزمودنى استفاده شود، ضمن اينكه انجام اين تحقيق

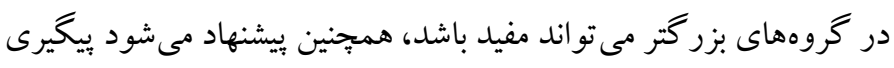
طولانى مدت براى بررسى اثربخشى درمان در طولانى مدت انجام گرددد، بيشنهاد مى شود يزو هش حاضر در مورد سنين و مقاطع تحصيلى تكرار شود.

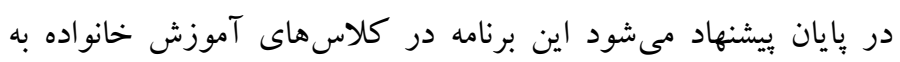

$$
\text { والدين ارائه شود. }
$$

\section{ملاحضات اخلاقى} بيروى از اصول اخلاق ثخوهش: اين مقاله بر كرفته از رساله دكتراى نويسنده اول در

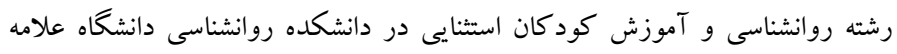

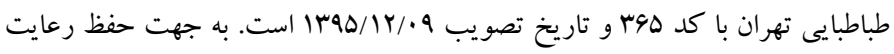

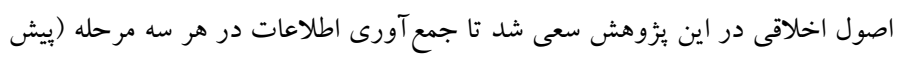

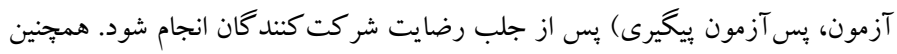

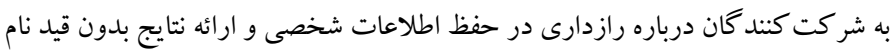
و مشخصات شناسنامه افراد، اطمينان داده شد.

حامى مالى: اين يُوهش در قالب رساله دكترى و بدون حمايت مالى مى باشد.

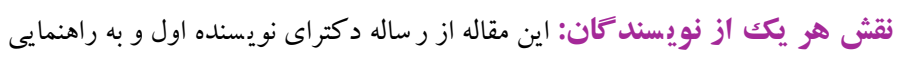

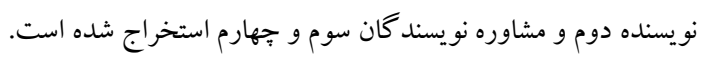

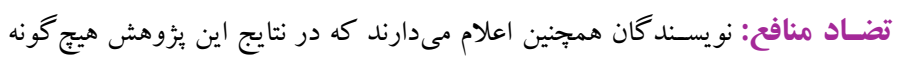
تضاد منافعى وجود ندارد.

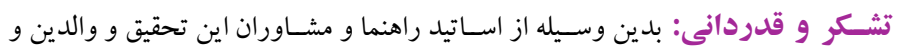
نوجوانانى كه در اين يثوهش شركت كردند، تشكر و قدردانى مى گردد.
در تبيين اين يافته مىتوان گفت كه مراحل حل مسئله به نوجوان كمك كان

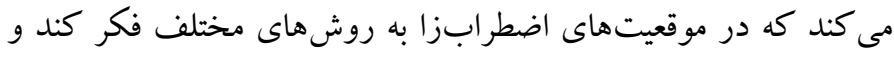

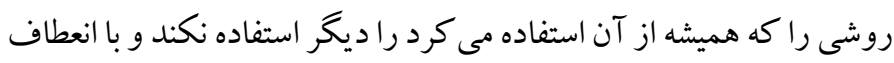

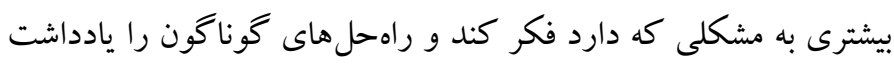

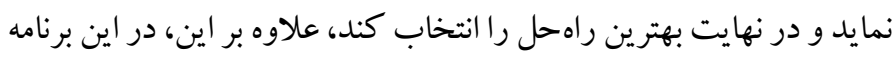

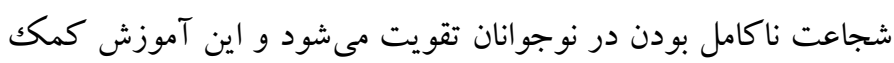

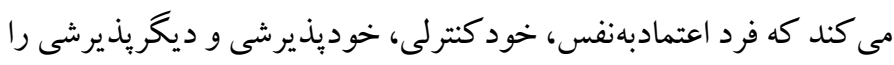

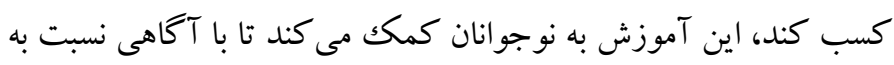

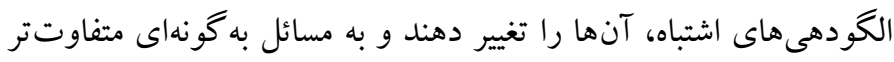

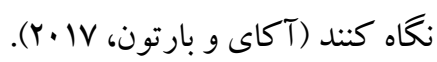
در تكنيك "طورى عمل كن كه انغار" كه يكى از تكنيكهاى برنامه

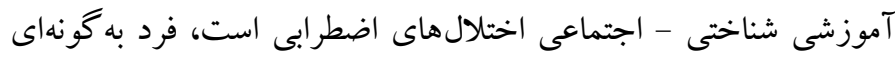
عمل مى كند كه دوست دارد يعنى هدف اين تكنيك اين است كه فرد از كنار مقاومت احتمالى عبور كند، خطرات ادراككشده را را خنثى كند، مثلاً،

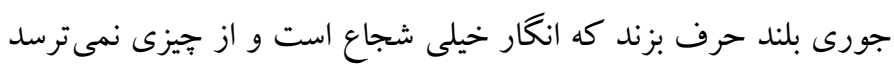

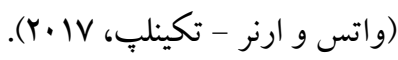
در يزوهش هاى صورت كرفته بيشتر بر فرزنديرورى دمو كر اتيك از طريق اجتناب از تنيبه، توجه به نتايج منطقى رفتار، تمايز بين انضباط و تنبيه تأكيد

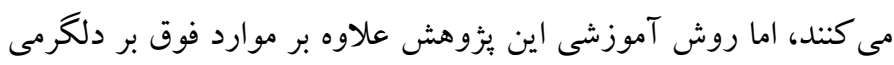



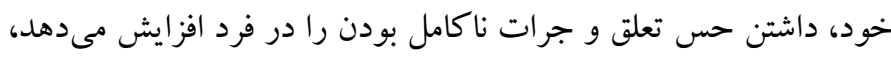

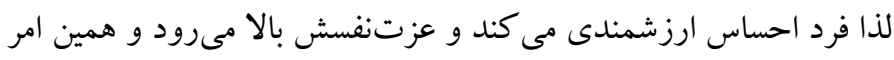

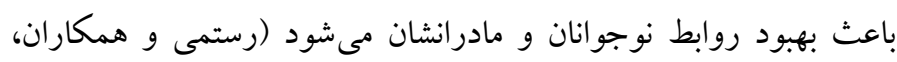

.$(1199$

همجنين در اين روش آموزشى بر تحريفهاى شناختى تأكيد شده است

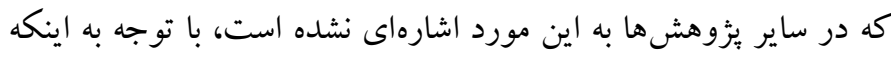

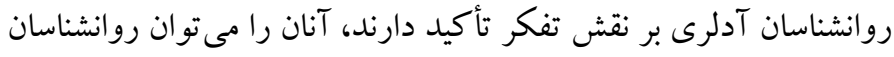
شناختى تلقى كرد. درمانكر هاى آدلرى، انحرافات شناختى فرد را مى يابند

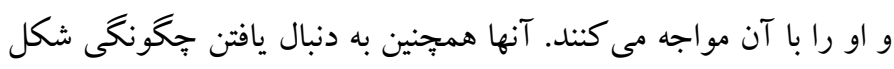

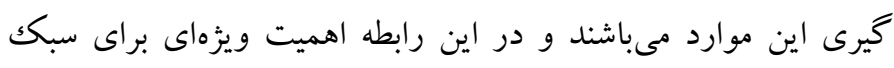

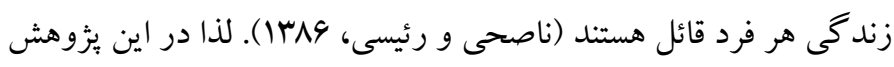




\section{References}

Abbasi, M., Neshatdoost, H. (2013). Effectiveness of Parent-Child Interaction Therapy on Reduction of Symptoms in Oppositional Defiant Disorder. Journal of Clinical Psychology, 5(3), 59-67. doi: 10.22075/jcp.2017.2136. (Persian). [link]

Araghi, Y. (2008). Comparison of the quality of parent Child Relationship of two Groups of Aggressive and Non Aggressive boy Students. Journal of Psychological Studies, 4(4), 113-129. doi: 10.22051/psy.2008.1644. (Persian). [link]

Akay, S., \& Bratton, S. (2017). The effects of Adlerian play therapy on maladaptive perfectionism and anxiety in children: A single case design. International Journal of Play Therapy, 26(2), 96. doi.org/10.1037/pla0000043. [link]

Bahlmann, R \& Dinter, L. D, (2001). "Encouragement Self Encouragement: An Effect Study of the Encouraging Training Schoenaker-Concept," The Journal of Individual Psychology, 57, 273-288. [link]

Bar-Haim, Y., Lamy, D., Pergamin, L., Bakermans Kranenburg, M. J., \& Van Ijzendoorn, M. H. (2007). Threat related attentional bias in anxious and nonanxious individuals: a meta analytic study. Psychological bulletin, 133(1), 1. doi: 10.1037/0033-2909.133.1.1. [link]

Bradford, A. B., Burningham, K. L., Sandberg, J. G., \& Johnson, L. N. (2017). The association between the parent-child relationship and symptoms of anxiety and depression: The roles of attachment and perceived spouse attachment behaviors. Journal of marital and family therapy, 43(2),291-307. doi: 10.1111/jmft.12190. [link]

Bettner, B. L. (2020). Are Alfred Adler and Rudolf Dreikurs Relevant for Parents Today?. The Journal of Individual Psychology, 76(1), 70-78. doi: 10.1353/jip.2020.0018. [link]

Colonnesi, C., Draijer, E. M., Jan JM Stams, G., Van der Bruggen, C. O., Bogels, S. M., \& Noom, M. J. (2011). The relation between insecure attachment and child anxiety: A meta-analytic review. Journal of Clinical Child \& Adolescent Psychology, 40(4), 630-645. doi:10.1080/15374416.2011.581623. [link]

Cooley, M. E., Veldorale-Griffin, A., Petren, R. E., \& Mullis, A. K. (2014). Parent-child interaction therapy: A meta-analysis of child behavior outcomes and parent stress. Journal of Family
Social Work, 17(3), 191-208. doi: 10.1080/10522158.2014.888696. [link]

Dillman Taylor, D., Meany-Walen, K. K., Nelson, K. M., \& Gungor, A. (2019). Investigating group Adlerian play therapy for children with disruptive behaviors: A single-case research design. International Journal of Play Therapy, 28(3),168. doi: 10.1037/pla0000094. [link]

Foster, T., Steen, L., O'Ryan, L., \& Nelson, J. (2016). Examining How the Adlerian Life Tasks Predict Anxiety in First Year Counseling Students. The Journal of Individual Psychology, 72(2), 104120. doi: 10.1353/jip.2016.0009. [link]

Hasani, J., Sheikhan, R., Aryanakia, E., Mahmoodzadeh, A. (2013). Adolescents social anxiety:the role of attachment styles and cognitive emotion regulation strategies. 9(36), 363-375. (Persian). [link]

Heydarnia, A., Charkhian, A. (2007). A Study on the Quality of Parental-Child Relationship in Addicted Adolescents versus Normal Ones. refah; 6 (25):3958. (Persian) [link]

Hudson J. L., \& Rapee, R. M. (2015). Parent child interactionsand anxiety disorders: An observational study. Behavior Therapy. 39(12), 1411-427. doi: 10.1016/s0005 7967(00)00107-8. [link]

Hughes, C. H., \& Ensor, R. A. (2009). How do families help or hinder the emergence of early executive function?. New directions for child and adolescent development, 2009 (123), 35-50. doi: 10.1002/cd.234. [link]

Ioffe, M., Pittman, L. D., Kochanova, K., \& Pabis, J. M. (2020). Parent-adolescent communication influences on anxious and depressive symptoms in early adolescence. Journal of youth and adolescence, 49, 1716-1730. doi: 10.1007/s10964020-01259-1. [link]

Karayağız, Ş., Aktan, T., \& Karayağız, L. Z. (2020). Parental Attachment Patterns in Mothers of Children with Anxiety Disorder. Children, 7(5), 46. doi: 10.3390/children7050046. [link]

Kendall, P. C., Safford, S., Flannery-Schraeder, E., \& Webb, A. (2004). Child anxiety treatment: Outcomes in adolescence and impact on substance use and depression at 7. 4-year follow-up. Journal of Consulting and Clinical Psychology, 72, 276287. doi: 10.1037/0022 006X.72.2.276. [link]

Kerns, K. A., Siener, S., \& Brumariu, L. E. (2011). Mother-child relationships, family context, and child characteristics as predictors of anxiety symptoms in middle childhood. Development and 
Psychopathology, 23(2), 593-604. doi.org/10.1017/S0954579411000228. [link]

Kermani, N., Tavakkoli, M., Fardi, M., Fereydounnezhad, M., banihashem, K. (2020). Role of creativity in organizational learning and social anxiety in teachers. Psychological Science, 19 (92): 10411048. (Persian) [link]

Khabbaz, M., Alizadeh, H., Delavar, A., Ebrahimi Ghavam, S., Rostami, R., \& Behjati, Z. (2016). The effectiveness of social interest fostering program (mother-child) on psychological basic needs satisfaction in students with oppositional defiant disorder. Journal of Applied Psychological Research, 6(4), 15-30. (Persian) [link]

Mohammadzadeh, A., Rezaei, A., \& Rostami, L. (2020).The relationship between paranoid and schizotypal traits with social anxiety and social problem solving among the students. Psychological Science. 19 (92): 981- 990. (Persian) [link]

Mahmoodian, M., Alizade, H., Pezeshk, P., Borjali, A., Farrokhi, N. (2018). Adler-Glasser approach to oppositional defiant disorder: a systematic review. Psychology of Exceptional Individuals, 7(28), 199214. doi: 10.22054/jpe.2018.32688.1788. (Persian) [link]

McVittie, J., \& Best, A. M. (2009). The Impact of Adlerian-Based Parenting Classes on Self Reported Parental Behavior. Journal of Individual psychology, 65(3). [link]

Nasehi, A., Raeisi, F. (2007). A Review of Adler's Theories. Advances in Cognitive Sciences; 9 (1): 55-66. (Persian) [link]

Roohi, A. (2014). Theoretical and Applicable Approaches in Anxiety Disorders in Children. J Except Educ; 3 (125):47-58. (Persian) [link]

Rostami, S., Toozandehjani, H., \& Nejat, H. (2019). The Comparison of the Effectiveness of Parent-Child Interaction Training and Adler-Dreikurs Parenting Training on Improving the Quality of the ParentChild Relationship in divorced Mother's Children. Journal of North Khorasan University of Medical Sciences, 11(3), 46-55. doi. 10.21859/nkjmd110307. (Persian) [link]

Vagos, P., \& Carvalhais, L. (2020). The impact of adolescents' attachment to peers and parents on aggressive and prosocial behavior: A short-term longitudinal study. Frontiers in psychology, 11.doi:10.3389/fpsyg.2020.592 44. [link]

Watts, R. E. (2017). Adlerian and constructivist therapies: A neo-Adlerian perspective. The Journal of
Individual Psychology, 73(2), 139155. doi:10.1353/jip.2017.0012. [link]

Watts, R. E., \& Ergüner-Tekinalp, B. (2017). Positive psychology: A neo-Adlerian perspective. The Journal of Individual Psychology, 73(4), 328337. doi:10.1353/jip.2017.0027. [link]

Wong, Y. J. (2015). The psychology of encouragement: Theory, research, and applications. The Counseling Psychologist, 43(2), 178-216. doi: 10.1177/0011000014545091. [link]

Zerach, G., \& Elklit, A. (2020). Attachment and social support mediate associations between Polyvictimization and psychological distress in early adolescence. International Journal of Psychology, 55(3),380-391. doi: 10.1002/ijop.12590. [link] 